Dhaka Univ. J. Biol. Sci. 28(2): 159-165, 2019 (July)

\title{
PSYCHOMETRIC PROPERTIES OF LOCK-WALLACE SHORT MARITAL ADJUSTMENT SCALE (LWSMAS) FOR BANGLADESHI COUPLES
}

\author{
Mosammat Nazma Khatun*, Farah Deeba and Tanzir Ahmmad Tushar ${ }^{1}$ \\ Department of Clinical Psychology, University of Dhaka, Dhaka-1000, Bangladesh
}

Key words: Couples, Marital adjustment, Adaptation, Item-analysis, Reliability, Validity

\begin{abstract}
The present study aimed to explore psychometric properties of the LockWallace Short Marital Adjustment Scale to use in the context of Bangladesh. The original scale consisted of 15 items and higher scores on the scale indicate greater marital satisfaction. After attaining agreement on the appropriateness of translated items by judges, item analysis was done using 318 clinical and nonclinical samples. The Cronbach's Alpha and split-half reliability of the adapted scale was 0.92 and 0.95 , respectively. The test-retest correlation was also found to be significant ( $\mathrm{r}=0.95, \alpha=0.01)$. Construct validity was measured by computing discriminant validity $(\mathrm{F}=38.88, \alpha<0.001)$ between the clinical and non-clinical sample. Convergent validity was also ensured by measuring correlation $(\mathrm{r}=0.72$, $\alpha=0.01$ ) between Lock-Wallace scale and Spanier's Dyadic Adjustment Scale. It is suggested that the scale be used in Bangladeshi context considering that the item may incur low score for couples.
\end{abstract}

\section{Introduction}

Marital adjustment continues across the family life cycle and as part of social sanctioning marriage allows people to live together to create a family. The concept of marriage is gradually changing all over the world but adjustment with couple's life at any social form is still a big concern. A great deal of research has been conducted over the past decades for exploring the predictors of success in marriage with unresolved methodological flaws ${ }^{(1)}$. Measuring the level of satisfaction or adjustment in married couple requires standard tool that encompasses all areas of family life. Despite the challenges several measures have been published to assess the quality of marital adjustment and are being used worldwide.

The Dyadic Adjustment Scale(2), Marital Satisfaction Inventory ${ }^{(3-5)}$ produce global rating of relationship satisfaction as well as satisfaction in other areas of functioning. Other measures have also been developed to assess cognitions and behavior patterns contributing to marital adjustment. The Relationship Belief Inventory ${ }^{(6)}$. The Inventory of Specific Relationship Standards ${ }^{(7)}$ and the Communication Patterns Questionnaire( ${ }^{(8,9)}$ are

*Author for correspondence: <nazmacp08@du.ac.bd>. ${ }^{1}$ Department of Psychology, University of Rajshahi, Rajshahi, Bangladesh. 
mostly used among many others. None of these scales are available in Bangla and adapted for the country. Although assessment in couple therapy mostly depends on clinical interview and observation, the standardized measures also provide significant guidelines for further investigation initially and an indicator of changes throughout the treatment or intervention process.

The result of violence against women survey conducted in 2011 identified that almost $87 \%$ of married women had ever experienced any type of violence by current husband ${ }^{(10)}$. The higher percentage of any type of violence is predominantly contributed by psychological violence. Almost $90 \%$ of those who have ever violated by current husband has the past 12-month experience of violence which implies the persistence nature of violence by the spouse. Recently it was found that in Bangladesh results among women ever married more than once indicate that $66 \%$ of them experienced violence by current as well as previous husbands while $98 \%$ have ever been violated by either current or previous husband(s)(11). Most of these couples are living with issues requires adjustment at different extent.

Mental health professionals are also providing services to improve adjustment of married couple. Both Bengali translated version of the Lock-Wallace short marital adjustment Scale ${ }^{(12)}$ and the Spanier's Dyadic Adjustment Scale(13)are used clinically in Bangladesh without its appropriate adaptation. These two scales have been translated properly for use in Bangladesh but it lacks standard adaptation so limits the robustness to use confidently both in clinical or research purposes. Moreover study conducted by Cross and Sharpley (1981)(14) suggested that the repetitions of items of Spainer's scale are not necessary to assess the marital adjustment. It also posed threats to use in clinical purpose. A pilot study has been conducted many years ago ${ }^{(15)}$ in the context of Bangladesh for the construction of a scale to measure marital adjustment that remained unused for the lacking of psychometric properties.

The 15-item self-report measure was developed by Locke and Wallace 1959(16) consisting items that had proven useful in previous studies(17). It asses a couple's satisfaction with their marriage, their agreement on key marital issues and their adjustment to each other. The self-report scale in content achieved its popularity over the past decades. Thus the present research aimed to adapt the scale for use in Bangladesh to contribute in clinical assessment, treatment and research purposes.

\section{Materials and Methods}

The study was conducted in three phases, these are, Phase-I: Judge evaluation of the translation, Phase-II: Item analysis and Phase-III: Determining reliability and validity.

A total sample comprised of 159 couples that is 318 married individuals $(\mathrm{M}$ age $=$ 35.51 years; $\mathrm{SD}=10.84$ ) was taken for the Phase-II study. To overcome the challenges to discriminate the well-adjusted and maladjusted couple, researcher selected couples who 
did not seek mental health services ever and did not feel distress in couple life as a nonclinical sample $(\mathrm{N}=222, \mathrm{M}$ age $=36.79$ years, $\mathrm{SD}=10.36)$ and those who sought active consultation to adjust their married life as clinical sample $(\mathrm{N}=96, \mathrm{M}$ age $=32.54$ years; $\mathrm{SD}$ =11.39). Demographic variables include varied age level (20 to 69) education (primary to postgraduate) and monthly income, which were approximately matched for both groups. A total of 30 couples ( $30 \times 2=60$ individuals) were selected purposively to see the testretest reliability of score in final scale. For measuring concurrent validity, the scales were administered solely to the couples (20) who were receiving treatment in the psychiatric clinic.

The Lock-Wallace Short Marital Adjustment Scale ${ }^{(16)}$. The scale is a 15-item self report measure and can be administered to both partners or to just one partner. Seven response points are given to indicate marital happiness in item-1, a six-point scale of agreement to responds to item-2 through 9, and scales tailored to each item for items 10 through 15. The score for each item responses are not exposed to the respondents. The item scores are summed for each individual. Scores can range from 2 to 58 and higher scores indicate greater marital satisfaction. Lock and Wallace reported the average score for those individuals who were in troubled marriage was 71.70 and for those in good marriage was 135.90. Among the sample of Lock and Wallace study, $17 \%$ of the individuals were in troubled marriages scored over 100 and $96 \%$ of the individuals in good marriages scored over 100. Split-half reliability was 0.90 in original study Locke ${ }^{(16)}$ and later Cross and Sharpley (1981)(14) found an alpha of 0.83 . Several researchers found the consistency between the scale score and the level of marital satisfaction regarding communication ${ }^{(17)}$, self-role congruence ${ }^{(18)}$, and multiple-role women ${ }^{(19)}$ which ensure the validity of the scale.

Spanier's Dyadic Marital Adjustment Scale ${ }^{(2)}$. The 32-item scale is designed for assissing the quality of marriage and four dyads (dyad is satisfaction, dyadic cohesion, dyadic consensus and affectional expression) with either married or unmarried cohabiting couples. Factor analysis revealed satisfactory relationship with theory and practical presence of constructs in population. Research evidence supported for content, criterion-related, and construct validity and high scale reliability. The Bengali version of the measure ${ }^{(13)}$ was used in the study to test validity for LWSMAS.

The first step focused on the translation of items and got experts' opinion for the accuracy of items in the context of Bangladesh. The research team translated the original scale initially. After careful review of research team, a panel of 15 judges was selected who were psychiatrists and clinical psychologists. The judges were requested to express their opinion on two points ratings either agreed or not agreed. A comment section was also provided if they suggested for further changes. Items were kept as it was on the $82 \%$ agreement of the judge's opinion. The suggestions provided by them were also implemented accordingly. 
For item analysis and determining psychometric properties, the Lock-Wallace scale was administered along with demographic sheet. To compute convergent validity Spanier's Dyadic Adjustment scale and Lock-Wallace scales were demonstrated to the participants who attended the psychiatric clinic. Before every administration participant were informed about the purpose of data collection and also clearly informed about their right not to take part in research.

\section{Results and Discussion}

The items of the final adapted version were selected through item analysis. Corrected item total correlation was computed to see the level of correlation that determined the validity of item in the context of Bangladesh. The item total correlation of coefficient is presented in Table 1. Discrimination value was also determined by computing analysis of variance between clinical and non-clinical samples. The discrimination value was found significant $[\mathrm{F}(1,316)=38.88, \mathrm{p}=0.0001]$ (Fig. 1). As item12 was found to have low level of item validity both in internal consistency and discrimination value, it requires further research to change the content of the item.

Table 1. Item total correlation coefficient.

\begin{tabular}{lcclcc}
\hline Items & $\begin{array}{c}\text { Corrected item } \\
\text { total correlation }\end{array}$ & $\begin{array}{l}\text { Cronbch's Alpha } \\
\text { if item deleted }\end{array}$ & Items & $\begin{array}{c}\text { Corrected item } \\
\text { total correlation }\end{array}$ & $\begin{array}{c}\text { Cronbach's Alpha } \\
\text { if item deleted }\end{array}$ \\
\hline 1 & $0.609^{*}$ & $0.819^{*}$ & 9 & $0.649^{*}$ & $0.812^{*}$ \\
2 & $0.647^{*}$ & $0.813^{*}$ & 10 & $0.434^{*}$ & $0.809^{*}$ \\
3 & $0.711^{*}$ & $0.811^{*}$ & 11 & $0.586^{*}$ & $0.804^{*}$ \\
4 & $0.746^{*}$ & $0.802^{*}$ & 12 & $0.140^{*}$ & $0.825^{*}$ \\
5 & $0.625^{*}$ & $0.813^{*}$ & 13 & $0.594^{*}$ & $0.797^{*}$ \\
6 & $0.680^{*}$ & $0.793^{*}$ & 14 & $0.459^{*}$ & $0.820^{*}$ \\
7 & $0.701^{*}$ & $0.811^{*}$ & 15 & $0.551^{*}$ & $0.803^{*}$ \\
8 & $0.762^{*}$ & $0.809^{*}$ & & & \\
\hline
\end{tabular}

*Correlation is significant at 0.01 level.

Reliability of the adapted version: Test-retest reliability and Cronbach-alpha were determined to find out the level of consistency of measures.

The Cronbach-Alpha: The Cronbach-alpha reliability was also found high $(\mathrm{r}=0.92)$ for the adapted version.

Test-retest reliability: The scale was administered within two weeks interval on a sample of 30 non-clinical couples. The correlation coefficient was also significant $(r=0.95$, $\alpha=0.01)$ as in the other methods. 


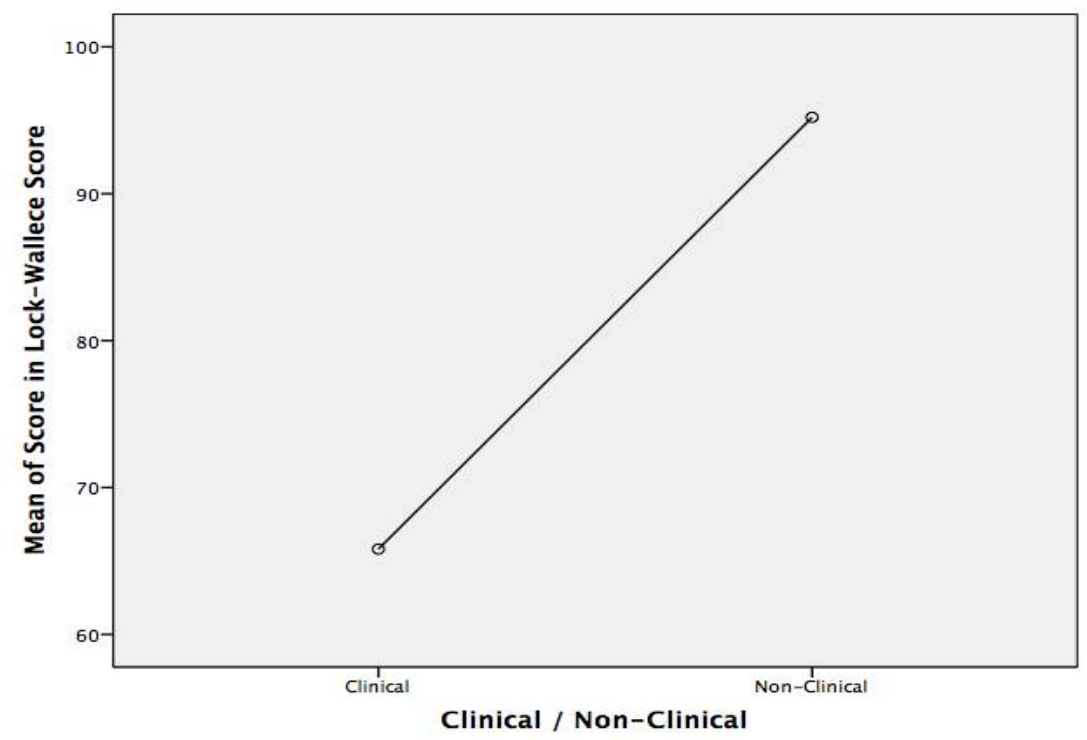

Fig. 1. Difference between scores of clinical and non-clinical participants on LWSMAS.

Validity of the Bengali version LWSMAS: Validity of the scale was determined by ensuring content validity and construct validity as these two methods are given importance by researchers ${ }^{(21,22)}$.

Content validity: The content validity of the original scale was highly satisfactory as reported by many research ${ }^{(18,19)}$. Content validity of the adapted version was censured by the expert opinion and by the professionals who were using the scale for long time in the context of Bangladesh.

Construct or criterion related validity: For measuring criterion related validity Spanier's Dyadic marital adjustment scale and the Lock-Wallace scale were demonstrated simultaneously on a sample of 20 couples who were receiving treatment in the psychiatric clinic. Positive correlation was found between the total score of the two scales.

The correlation coefficient between the two scales ensured the convergent validity of the items. The average score of the non-clinical sample was $95.20(\mathrm{SD}=39.37)$ whereas for the clinical sample it was 65.81 ( $\mathrm{SD}=36.71$ ).

The main purpose of the present study was to explore the psychometric properties of the Lock-Wallace Short Marital Adjustment Scale. As discussed earlier, the number of people who are seeking treatment for marital distress is increasing gradually. Mental health professionals have to face this issue but depending mostly on observation and interview method to assess the area of marital adjustment. Besides constructs those are contributing to marital adjustment are also not well grounded in the context of Bangladesh which is necessary to formulate a new scale. The present scale was selected 
as it was found a highly reliable and valid to measure the construct of marital adjustment.

Table 2. Correlation between total scores of Locke-Wallace Scale ${ }^{(16)}$ and Spanier's Dyadic Adjustment Scale ${ }^{(20)}$.

\begin{tabular}{llcc}
\hline Name of the scale & $\mathrm{N}$ & 1 & 2 \\
\hline 1. Lock-Wallace Scale & 20 & - & $\mathrm{r}=0.725^{* *}$ \\
2. Dyadic Adjustment Scale & 20 & $\mathrm{r}=0.725^{* *}$ & - \\
\hline
\end{tabular}

${ }^{* *} \alpha=0.01$.

Adaption of any tool largely depends on the equivalence of structural formation and meaning of language attributed to the item of the scale. Judges' evaluation strictly fulfilled the scale's content validity for 15 items of the scale. After forward translation and judges feedback item analysis and discrimination value was determined to ensure the consistency of items. All the 14 items of the scale except item 12 showed high level of internal consistency and discrimination value that is presented in Table 1. Finally, the reliability and validity was explored as the indicator of psychometric properties of the scale for use in Bangladesh. The Chronbach-alpha reliability (0.92), and test-retest reliability (0.95) indicated the scale's high level of consistency over time. The correlation between the Spanier's scale and Lock-Wallace scale also supported convergent validity $(\mathrm{r}=0.72)$ of the present scale.

Moreover, the 15-item scale will be most suitable to apply in clinical practice with a minimal time. So this scale will be equally compatible to administer in research purposes though it has no norms. But the average score of distressed and healthy couple will be a major determinant of the couple's marital adjustment as it was for the original scale. Despite of the multiple utility the adaptation process was also contained limitations.

\section{References}

1. Weiten W and AM Lloyd 1994. Psychology Applied to Modern Life Adjustment in the 90s. California: Brooks Kole Publishing Company.

2. Spanier GB 1976. Measuring dyadic adjustment: New scale for assessing the quality of marriage and similar dyads. Journal of Marriage and Family 38: 15-28.

3. Snyder DK 1979. Multidimensional assessment of marital satisfaction. Journal of Marriage and the Family. 813-823.

4. Snyder DK 1981. Marital satisfaction inventory (msi): Manual. Western Psychological Services.

5. Snyder DK, RM Wills and TW Keiser 1981. Empirical validation of the marital satisfaction inventory: An actuarial approach. Journal of Counseling and Clinical Psychology 49(2): $262-268$.

6. Eidelson, RJ and N Epstein 1982. Development of a measure of dysfunctional relationship beliefs. Journal of Consulting and Clinical Psychology 50: 715-720. 
7. Baucom DH, N Epstein, LA Rankin and CK Burnett 1996. Assessing relationship standards: The Inventory of Specific Relationship Standards. Journal of Family Psychology 10: 72-88.

8. Christensen A 1987. Detection of conflict patterns in couples. In: K. Hahlweg and M. J. Goldstein (Eds.), Understanding major mental disorder: The contribution of family interaction research (pp. 250-265). New York: Family Process.

9. Christensen A 1988. Dysfunctional interactional patterns in couples. In: P. Noller and M. A. Fitzpatrick (Eds.), Monographs in socila psychology of language: No. 1. Perspectives on marital interaction (pp. 31-52). Clevedon, England: Multilingual Matters.

10. Bangladesh Bureau of Statistics, BBS 2011. Violence Against Women Survey 2011. Dhaka, Bangladesh: Bangladesh Bureau of Statistics (BBS).

11. Bangladesh Bureau of Statistics (BBS) 2013.Violence Against Women Survey, Dhaka,. Bangladesh.

12. Khatun NM andF Deeba 2009. Bengali version of Locke-WallacheShort Marital Adjustment Scale, Unpublished manuscript, University of Dhaka.

13. Ilyas QSM 1986. Adapted Bengali version of Spaniers Dyadic Adjustment Scale. Unpublished thesis, Department of Psychology, University of Dhaka.

14.Cross DG and CFSharpley 1981. The Lock-Wallace Marital Adjustment Test reconsidered: Some psychometric findings in regards to its reliability and factorial validity. Educational and Psychological Measurement 41: 1303-1306.

15.Islam N and A Anwar 1996. Construction of a Scale to Measure Marital Adjustment: A Pilot Study. Bangladesh Psychological Studies 6: 52-65.

16. Locke HJ and KM Wallace 1959. Short Marital-Adjustment and Prediction Tests: Their reliability and validity. Marriage and Family Living 21: 251-255.

17. Schachter, J and KD O'leary1985.Affective intent and impact in marital communication. The American Journal of Family Therapy 13(4): 17-23.

18. Chassin L, A Zeiss, K Cooper and J Reaven 1985. Role perceptions, self-role congruence, and marital satisfaction in dual-worker couples with preschool children. Social Psychology Quarterly 48: 301-311.

19.McLaughlin M, LS Cormier and WH Cormier 1988. Relationship between coping strategies and distress, stress, and marital adjustment of multiple-role women. Journal of Counseling Psychology 35: 187-193.

20. Spanier GB 1976. Measuring dyadic adjustment: New scales for assessing the quality of marriage and similar dyads. Journal of Marriage and the Family. 15-28.

21. Anastasi A 1982. Psychological testing (5th ed.). New York: Macmillan.

22.Aiken LR 1985. Three coefficients for analyzing the reliability and validity of ratings. Educational and Psychological Measurement 45: 131-142. 